\title{
El agregado de fluoruros tópicos al uso de pasta dental reduce la formación de caries
}

\section{Objetivo}

Revisar la evidencia científica para determinar si existen efectos beneficiosos en la prevención de caries en niños y adolescentes cuando sumamos la utilización de fluoruros tópicos en forma de enjuague bucal, geles o barnices al uso de pasta dental fluorada.

\section{Fuentes de Datos}

Los autores buscaron en los Registros de Estudios de la Cochrane Oral Health Group, Registros Centrales de Estudios Controlados Cochrane, MEDLINE, EMBASE, SCISEARCH y SSCISEARCH, ISTP, BIOSIS, CINAHL, ERIC, DISSERTATION ABSTRACTS, y LILACS/BBO.

\section{Selección de Estudios}

Los autores seleccionaron estudios clínicos controlados y aleatorizados o cuasi- aleatorizados ${ }^{*}$ que hubieran utilizado o indicado evaluación de resultados ciegos, en la que una forma de Terapia Fluorada Tópica (pasta dental, enjuagues bucales, barnices o geles) es comparada con otra combinada con ella; y que hubieran durando como mínimo un año calendario escolar en niños y adolescentes hasta 16 años, independientemente del nivel inicial de caries, exposición o no a fluoruros, niveles de tratamiento dental o nacionalidad. El resultado principal es el incremento del desarrollo de caries a través del índice CPOs (Cariados, Perdidos, Obturados por superficie dentaria.)

\section{Extracción de datos}

Los datos fueron recolectados por un revisor que utilizó formularios pilotos para extracción de datos. Un segundo revisor extrajo al azar datos de aproximadamente un tercio de los estudios incluidos. Cuando fue necesario, un tercer revisor fue consultado para llegar a un consenso.

\section{Resultado principal}

Los nueve estudios seleccionados (4026 niños) proveyeron evidencia que demuestra que el uso simultáneo de fluoruros tópicos y pastas dentales potencia el efecto inhibitorio de la formación de caries comparado con la sola utilización de pasta dental (ver tabla)

Tabla. Resultado Principal

\begin{tabular}{c|c|c|c} 
Resultado & Fraccion Prevenida Promedio & $\mathbf{l C 9 5} \%$ & $\mathbf{p}$ \\
\hline $\begin{array}{c}\text { Indice CPOS Tratamiento } \\
\text { combinado vs. Pasta sola } \\
(\mathrm{n}=4026)\end{array}$ & $10 \%$ & 2 al $17 \%$ & 0.01 \\
\hline
\end{tabular}

No se observó heterogeneidad* significativa.

Un meta-análisis independiente de gel de fluoruro o enjuagatorio combinado con pasta sola favoreció el régimen combinado, aunque no fue estadísticamente significativa. Se observó un beneficio significativo del uso combinado de barniz y pasta pero solamente en un ensayo pequeño y parece espurio. No todas las combinaciones de valor práctico fueron evaluadas en ensayos. El único resultado estadísticamente significativo adicional favoreció el uso combinado de gel de fluoruro y enjuagatorio en relación al gel solo (beneficio ponderado 23\%; IC95\% 4 a 43\%; p 0.02), basado en dos ensayos.

\section{Conclusiones}

Debido a que el efecto preventivo de caries es relativamente pequeño y que ninguno de los estudios evaluó consistentemente efectos adversos de una terapia combinada, los autores no consideran posible realizar una clara recomendación sobre la superioridad de adicionar terapias tópicas fluoradas al uso de pastas dentales.

\section{Comentario}

La utilización de fluoruros como preventivos y remineralizantes de caries ha sido ampliamente estudiada y documentada'. Pueden ser administrados de forma sistémica y/o tópica². La forma sistémica es la que entra al organismo a través de la ingestión y se incorpora dentro de la estructura dentaria, durante el período pre-eruptivo, reemplazando los cristales de hidroxiapatita, por los de fluorapatita, mucho más resistentes al ataque ácido y por lo tanto, a la formación de caries. Ingresan a nuestro organismo a través del agua fluorada, gotas o tabletas. Es oportuno recordar por ejemplo, que el agua corriente en Capital Federal no tiene la dosis de flúor adecuada $(0,7$ a 1,2 ppm) motivo por el cual indicamos los suplementos de gotas o tabletas.

El flúor tópico es aquel que provee el ion a las superficies expuestas de las piezas dentarias a elevadas concentraciones, logrando un efecto de protección local. Los geles y barnices son de aplicación profesional, de alta concentración y baja frecuencia. Las pastas dentales y enjuagues bucales son de auto aplicación, de baja concentración y alta frecuencia.
Volviendo al estudio de referencia, si bien las pastas dentales son de baja concentración, su alta frecuencia de uso, por lo menos dos veces al día, consigue una eficacia muy grande, por lo que no lograríamos efectos adicionales importantes si adicionamos otras formas de flúor. Pero, ¿estamos seguros que los niños y adolescentes se cepillan los dientes al menos dos veces por día? Y si el niño se cepilla solo, ¿estamos seguros que tiene la habilidad manual adecuada como para lograr una buena técnica de cepillado y depositar el flúor en los lugares que son necesarios? Si no contamos con esta seguridad, deberíamos considerar aplicaciones tópicas profesionales que nos aseguran la llegada del flúor a los lugares necesarios en la boca.

\section{Conclusiones del comentador}

A la hora de indicar fluoruros las opciones son varias. La clave fundamental de la elección es un diagnóstico adecuado y personalizado de cada uno de nuestros pacientes, considerando la edad, el lugar de residencia y el riesgo cariogénico, para lograr una efectiva prevención de las caries.

\section{Referencias}

1. CDC. Recommendations for using fluoride to prevent and control dental caries in the United States. MMWR. 2001;50 (RR-14):1-42

2. American Academy of Pediatric Dentistry Clincal Guideline on Fluoride Therapy. 2003 